\title{
Specialisation, standardisation and Lapita ceramics
}

\author{
Geoffrey Clark
}

Department of Archaeology and Natural History, Research School of Pacific and Asian Studies, The Australian National University, Canberra ACT 0200, Australia. geoffrey.clark@anu.edu.au

\section{Introduction}

In anthropological theory, craft specialisation is a defining feature of complex societies, and is viewed as a key factor in the development of the political economy (Costin and Hagstrum 1995; Longacre 1999). Specialisation is the investment of labour and capital in the production of a particular good or service beyond what is required for domestic consumption, with surpluses providing the capital required for economic exchanges (Benco 1988). Craft specialisation is closely linked to the standardisation of material culture because the production of goods in large quantities is facilitated when artisans reduce the amount of artefact variability (Costin and Hagstrum 1995; Rice 1981). For ceramics, the standardisation hypothesis holds that a high-degree of similarity in vessel characteristics (physical and stylistic) reflects specialised production, such as from a workshop, while heterogeneity indicates dispersed household production (Benco 1988). Among Pacific cultures, communities which specialised in manufacturing and trading pottery developed in late prehistory, and they have been documented, particularly, in coastal New Guinea (Allen et al. 1997; Irwin 1985; Vanderwal 1973).

Craft specialisation has also been advanced as a potential explanation for the similarity of Lapita culture ceramics dated to 3300-2600 cal. BP, a proportion of which includes vessels marked with distinctive dentate-stamped designs, among other types of decoration (Bedford 2006; Summerhayes 2001). For instance, some Lapita communities might have specialized in making and exporting pots (Chiu 2003; Green 1982; Hunt 1988:57), using a uniform and potentially specialised production technology (Bellwood 1978:258; Golson 1971), 
with the possibility that Lapita pottery was made by women and used by men in maritime trade networks (Marshall 1985).

Recent compositional study of Lapita ceramics does not support, however, the idea of standardised pottery production and bulk transport over long distances (Chiu 2003; Summerhayes 2000; but see Hunt 1989), although a few pots certainly accompanied migrants between archipelagos (Burley and Dickinson 2001). Rather, as Summerhayes $(2001: 57,60)$ recognized in his analysis of pottery from the Bismarck Archipelago, a fundamental divide exists within early Lapita ceramics between 'specialised' highly decorated vessels and utilitarian 'standardised' wares.

The presence of both specialised, and standardised sets of ceramics within Lapita assemblages is an exception to the standardisation hypothesis. It is an exception also found in complex societies, when specialists produce goods for elites. Such items may be extremely heterogeneous in their size, decoration and materials, as elite patrons sponsor the production of goods whose value in the political economy stems from their uniqueness. There is little evidence, as yet, that Lapita groups were highly stratified with a strict division between craft specialists, that in the case of ceramics might be recognised by limited variation in the raw materials used to construct pots.

As specialised ceramic production is not demonstrated, we must posit a specialized function for highly decorated Lapita ceramics, and interrogate the politically and socially symbolic dimensions of the pottery (e.g. Best 2002; Chiu 2005; Kirch 1997; Spriggs 1990; Summerhayes 2000). These aspects should be most apparent in vessels that signify a high labour cost relative to utilitarian wares, identifiable from their size, complexity and quantity of formal decoration. Establishing the size of Lapita vessels is important as the amount of social information displayed on a ceramic container relates both to the size of the design field, which is a function of vessel size, and also of design density (the number of decorative elements in a defined area).

In this paper, I examine how 'specialised' and 'standardised' Lapita ceramics might be distinguished, and explore the hypothesis that highly decorated 'specialised' Lapita vessels were used in public contexts and were actively signalling or messaging Lapita groups. If that is the case, we would expect such vessels to have increased social visibility, and to be larger than utilitarian/domestic ceramics, and to also carry substantially greater amounts of decoration than domestic wares.

\section{Comparing Lapita Vessels}

Estimating the amount of variability in decorated versus utilitarian components of a Lapita assemblage is made difficult by the degree of container fragmentation, and the constraints on reconstructing accurately the physical dimensions of ceramics from sherds (e.g. DeBoer 1980; Plog 1985). Finds of complete or substantially complete prehistoric ceramic vessels have been reported from several parts of the Pacific, including Lapita contexts, and these vessels provide a more reliable indication of vessel size and the amount of decoration than do reconstructions derived from small sherds. However, a focus on the decorated component of Lapita assemblages, termed 'dentate-centric' by Summerhayes (2001:54), has dominated research, and as a result there is little detailed information about the utilitarian pottery used by Lapita groups that can be used to compare 'specialised' decorated vessels with 'standardised' utilitarian wares within a single assemblage. As a result it is not currently feasible to undertake an intra-assemblage analysis with published information to directly examine the idea that decorated Lapita ceramics were larger than utilitarian pots.

The idea might be tested, at least in a preliminary fashion, at the inter-assemblage level because of different rates of change in the decorated ceramic component compared with utilitarian pottery. According to Summerhayes (2001), the specialised dentate-stamped vessels changed rapidly during the early Lapita era 
in the Bismarck Archipelago, while the utilitarian pottery displayed little change, suggesting continuity in domestic function. Although Lapita pottery clearly has distinct regional expressions, which underwent specific transformations in particular archipelagos and islands (Burley et al. 2002; Chiu 2003; Sand 2001), there is a general trend over time for the simplification of vessel forms and a reduction in the amount of decoration, especially dentate-stamping. These changes have been interpreted as signalling the transition to a predominantly utilitarian/domestic set of ceramics and the elimination of specialised pottery vessels (Kirch 1990; Summerhayes 2000). By contrasting a set of specialised 'early' Lapita vessels from one location with predominantly utilitarian vessels from a 'late' Lapita site at another, we can begin to examine how 'specialised' Lapita ceramics were differentiated by their size and amount of decoration from domestic-utilitarian ceramics.

In New Caledonia an early Lapita ceramic assemblage of reconstructable vessels dated to ca. 3000 cal. BP was found in a pit discovered eroding from the WKO013A site (Sand et al. 1998). In the pit were two carinated high-necked jars which had had their bases broken before burial (Sand 1999:34). Around and over the two pots, base and rim sections from another 17 vessels had been layered, including remains of a vessel with a flat base. The context, size and number of vessels buried in the pit strongly indicates the vessels had a nonutilitarian function (Sand 1999). The dimensions of ten decorated carinated jars from the WKO013A site were derived from the published vessel profiles and vessel measurements (Sand 1999, 2001; Sand et al. 1998).

A late-Lapita assemblage of pots and bowls dating to $2600 \mathrm{cal}$. BP has been excavated from the Sigatoka Sand Dunes in Fiji (Birks 1973; Burley and Dickinson 2004). The pot assemblage probably represents utilitarian cooking pots as these vessels have a relatively low frequency of red slip and burnishing in the exterior, and a high frequency of carbon deposits, suggesting they were used to cook food (Birks 1973:21). In the typology of Birks (1973), expanded-rim vessels were included in three types of 'cooking pot' (Type 1A, 1B and 1C), which were differentiated from each other by minor variation in the neck and body. Birks (1973:24) noted that the vessel typology was subjective and his three types overlapped. To maintain consistency in vessel type, only pots with distinctive expanded rims (also known as 'collar rims'), with an ovoid-to-sub-globular body, illustrated in Birks (1973) were used in the analysis $(n=35)$. In the sample $46 \%$ of the expanded rim pots had a carbonised residue on the interior vessel surface, suggesting they were used to cook food.

For this study ceramic profiles were scanned and digitally enlarged to the vessel dimensions (e.g. maximum body width and vessel height) reported in Birks (1973), or in the case of the New Caledonian carinated jars, vessel profiles were scaled using a single measurement or associated scale units - a process which is likely to involve a larger amount of error than resizing vessels which have multiple measurements. Image distortion was minimized by removing the illustrations from the publication binding before scanning. Vessel profiles were traced and resized with Adobe Illustrator 9.0. The percentage of a vessel carrying decoration was calculated by measuring the profile area covered with tool designs, and comparing the value to the total vessel area (profile error estimate $\left.\pm 2-4 \mathrm{~cm}^{2}\right)$. Design density was measured on the vessel scans by placing a $10 \mathrm{~cm}^{2}$ square divided into $1 \mathrm{~cm}^{2}$ units on the design field, and counting the number of squares with tool-made decoration.

\section{Size variation in Lapita vessels}

The analysis of ceramic size from digital profiles and outlines from the only two assemblages, with an adequate number of reconstructed vessels and of an appropriate antiquity, was made to investigate three questions about the proposed division of Lapita assemblages into a specialised set of ceramics and a standardised group of utilitarian vessels:

1. Are carinated vessels from New Caledonia larger than the utilitarian, expanded-rim pots from Fiji, indicative of a specialised vessel used in public contexts? 
2. Is the amount of decoration on New Caledonian vessels significantly greater than that of late Lapita pots from Fiji, consistent with their having a signalling or messaging role in Lapita society?

3. Does the size variability of pots with expanded rims from Fiji indicate a standardised 'utilitarian' assemblage?

\section{Specialized vessels: size comparison}

The scaled vessel profile of 10 carinated vessels from New Caledonia and 35 expanded-rim pots from Fiji is shown in Figure 1. Both sets of vessels exhibit substantial size variation, but it is clear that the carinated vessels from New Caledonia are generally larger than those from Sigatoka in Fiji. The size variation in the carinated jar sample suggests three distinct size classes (small, medium, large), although this may be an artefact of the small sample. Two carinated jars are missing sections from the neck and rim, but based on body width, both are in the 'large' size range.

Except for one expanded-rim vessel (Birks Vessel No.82), all of the utilitarian cooking pots from Sigatoka have smaller dimensions than the 'medium' and 'large' jars from New Caledonia, and are approximately equal to, or slightly larger than, the two smallest carinated vessels. The carinated jars have a lip diameter that is $73-88 \%$ of maximum body width, and a vessel height ranging from $65-86 \%$ of maximum body width. The latter variability indicates a difference between carinated jars that have a body that is deeper than the height of the carination, and those with a body height that is similar to the carination height. Regardless of carinated jar size, there is a strong linear correlation between vessel height and maximum body width $\left(r^{2}=0.96\right)$, which is likely to indicate either vessel production by a small group of potters, or manufacture of a vessel type with defined proportions.

The large size and stylised shape of the carinated jar demonstrates considerable artisan skill and a high labour investment that is consistent with their having a specialised function and high social visibility.

If carinated jars also had active role in public contexts, then the amount and density of decoration placed on them should be significantly greater than the decoration found on ceramics made for domestic cooking and storage.

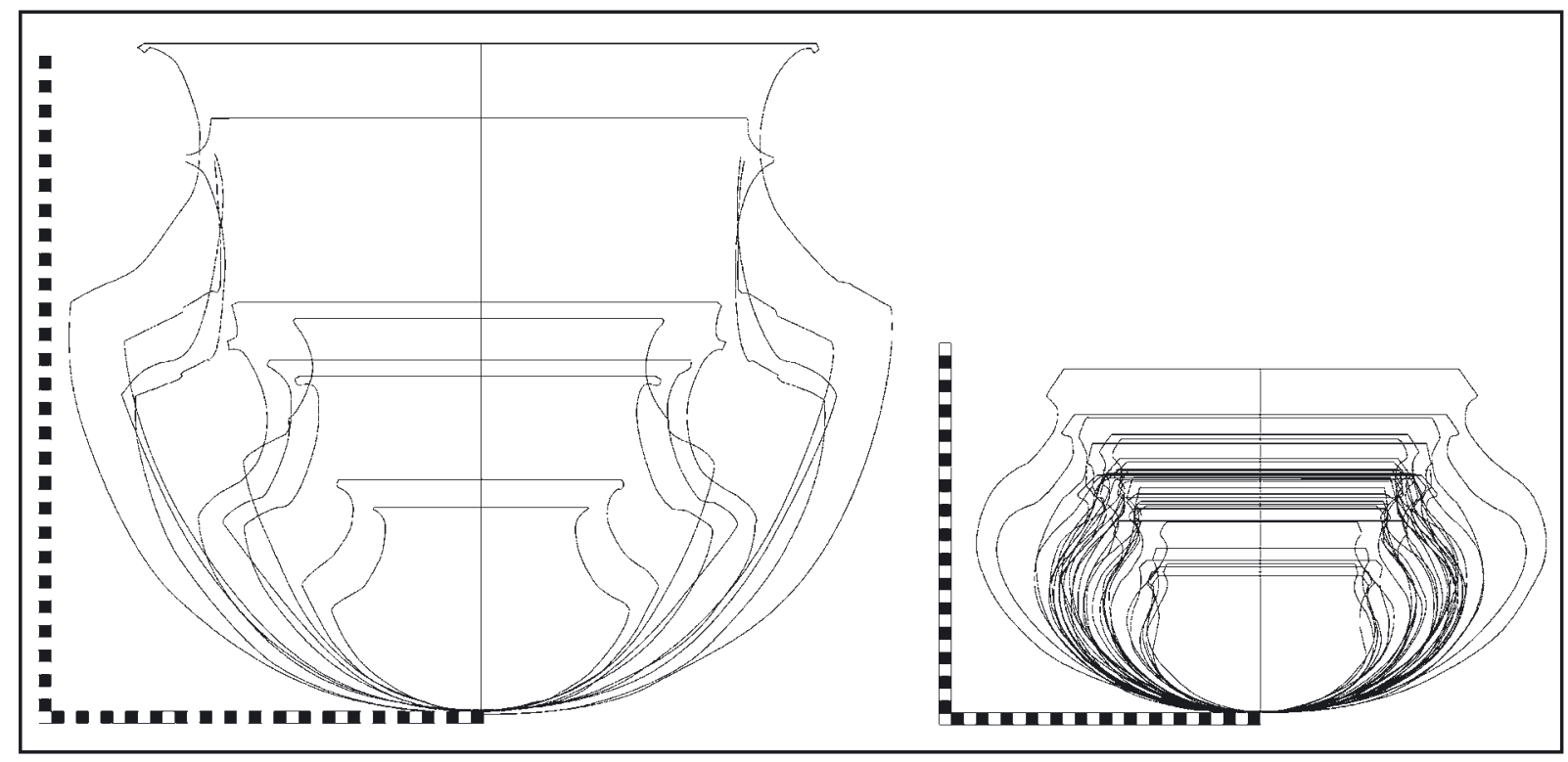

Fig. 1. Scaled vessel profiles of 10 carinated jars from New Caledonia and 35 expanded-rim pots from Sigatoka. The Sigatoka vessels scanned from Birks (1973) were numbers: 4, 6, 10, 21, 26, 29, 37, 40, 48, 50, 61, 66, 67, 68, 69, 71, 72, 79, 82, 86, $88,89,90,94,95,99,101,103,111,112,113,117,121,122,141$. Note that two of the carinated jars from New Caledonia are missing sections of the upper rim. Scale bars in $\mathrm{cm}$. 


\section{Specialized vessels: decoration comparison}

The carinated jars were all dentatestamped, except for one vessel that was incised (Sand et al. 1998), while the Sigatoka pots were tool impressed (nail, shell, other tool, $n=21)$, incised $(n=6)$, excised $(n=1)$ and dentate-stamped $(n=1))$.

The design area of the New Caledonian jars measured on vessel profiles varied from ca. $1000 \mathrm{~cm}^{2}$ for the largest jars and ca. $140-210 \mathrm{~cm}^{2}$ for the smallest jars. By comparison, six of the 35 late-Lapita pots from Sigatoka were plain $(17 \%)$, and the remainder had a decorated area ranging from ca. 18 to $80 \mathrm{~cm}^{2}$, substantially less than any of the carinated jars.

Similarly, the density of decoration measured by the number of $1 \mathrm{~cm}^{2}$ squares with tool decoration in a grid of $100 \mathrm{~cm}^{2}$ was high for the carinated jars, with a design area of ca. $80-100 \mathrm{~cm}^{2}$, compared with ca. 7-30 $\mathrm{cm}^{2}$ for the expanded rim vessels from Fiji.

The proportion of vessel decoration also differentiates the carinated jars, which had 39-56\% of the vessel surface carrying decoration, while the decoration percentage on the Sigatoka pots ranged from 0 to $14 \%$. Figure 2 shows the unambiguous separation between the two assemblages achieved by plotting design density against vessel decoration percentage.

A much greater amount of decoration on the New Caledonian vessels is consistent with a messaging/ signalling purpose, with the social information conveyed by the designs amplified by the large size of the vessels.

\section{Standardization and utilitarian ceramics}

The specialised function of the early Lapita carinated jars from New Caledonia was suggested by their deliberate interment, and is also supported by the above analysis of vessel size and decoration. The contrast between specialised and standardised sets of vessels should also be demonstrated by the reduced size variability of utilitarian vessels as a result of economic constraints imposed by the domestic environment. A commonly used statistic to measure size variation is the coefficient of variation (CV), which is the standard deviation of a sample multiplied by 100, divided by the sample mean. The resulting figure expresses the percentage variance around the sample mean. For the 35 expanded rim pots from Sigatoka, the CVs for three measurements (vessel height, maximum body width and external orifice diameter) ranged from $18 \%$ to $23 \%$, while the same measurements from the eight New Caledonian carinated jars gave CVs of 33-41 \% (Table 1), bearing in mind that some of the CVs include an unknown error margin as they are based on measurements derived from scaled vessel profiles.

The lower CVs of the Sigatoka pots show an assemblage which overall has a reasonably high amount of size variability, even though the CVs are much less than those of the New Caledonia carinated jars. This might be due to the inclusion of vessels that were made by potting communities separated by a century 
Table 1. Measurement variation in reconstructed ceramics from New Caledonia (Early Lapita carinated jars from Site WK0013A), Fiji (Late Lapita utilitarian pots from Level 1, Sigatoka), and Island New Guinea (20th century, Mailu Island). All measurements in $\mathrm{cm}$. CV = coefficient of variation (percent variance around the mean).

\begin{tabular}{lccc}
\hline & Fiji: Sigatoka & & \\
\hline Expanded rim pots $(\mathrm{n}=35)$ & MEAN & STDEV & CV \\
Max. body width $(\mathrm{cm})$ & 29 & 7 & 23 \\
Vessel height $(\mathrm{cm})$ & 18 & 4 & 21 \\
Ext. orifice $(\mathrm{cm})$ & 22 & 4 & 18 \\
\hline & New Caledonia: WK0013A & CV \\
\hline Carinated jars $(\mathrm{n}=8)$ & MEAN & STDEV & 33 \\
Max. body width $(\mathrm{cm})$ & 42 & 14 & 41 \\
Vessel height $(\mathrm{cm})$ & 32 & 13 & 35 \\
Ext. orifice $(\mathrm{cm})$ & 34 & 12 & $\mathrm{CV}$ \\
& Island New Guinea: Mailu & & 12 \\
\hline Utilitarian vessels $(\mathrm{n}=59)$ & MEAN & STDEV & 12 \\
Vessel height $(\mathrm{cm})$ & 21 & 3 & 13 \\
Orifice $(\mathrm{cm})$ & 31 & 4 & 1 \\
Rim height $(\mathrm{cm})$ & 6 & & \\
\hline
\end{tabular}

or more, and the production of different-sized pots reflecting functional variation and/or social divisions (Blackman et al. 1993).

The emic categories employed by prehistoric potters is likely to increase the amount of variation in an archaeological sample, making the identification of standardisation difficult. However, if utilitarian containers were primarily manufactured for a domestic purpose, and container size was under the deliberate control of a potter, then a vessel size analysis might be used to identify similar-sized pots that also had a similar function, or groups of vessels that potters might have recognized as being suitable for a particular task.

A K-means cluster analysis was performed on 35 late-Lapita pots from Sigatoka using three measurements (Max. width, Vessel height, Ext. orifice) using SPSS. The K-means algorithm separated the data into a number of spherical clusters by determining a cluster centre and comparing vessel measurements to a cluster in an iterative process (Hintze 1997). The cluster analysis identified three size groupings, with a group of small pots $(n=7)$ and a group of the largest pots $(n=2)$, surrounding a middle group containing the majority of vessels. Excluding the smallest and the largest pots, CVs for the middle group of 26 vessels varied between $9 \%$ and $12 \%$. These values compare well with a sample of 59 utilitarian containers made by the pottery producing community on Mailu in island New Guinea recorded by Irwin (1985), which have CVs of $12-13 \%$ (Table 1).

\section{Discussion and Conclusion}

The analysis of Lapita ceramics often focuses on the comparison of dentate-stamped and incised designs, but vessel size is also an important indicator of a specialised function. The size of a ceramic container constrains the dimensions of the decorative 'canvas', with large vessels able to exhibit more decoration than small vessels. When the size of a ceramic vessel is enlarged to accommodate and expose greater amounts of decoration, potters have to invest more time on manufacture and embellishment, compared with utilitarian containers. Large vessels also tend to be harder to produce than small vessels, due to 
the difficulty of controlling thermic variation in a large clay object under open firing conditions (Clough 1992:182; Gosselain 1992).

The presence of large handmade ceramics indicates a high labour input and specialised vessel function. Despite this correlation, ceramicists have not been able to explore systematically size variability in Lapita assemblages due to the degree of fragmentation in excavated collections, with the result that the division of early Lapita vessels into 'standardised-decorated' and 'specialised-utilitarian' sets has received little empirical testing. In this study vessel reconstructions were scanned and resized allowing a novel comparison of early Lapita and late Lapita container profiles, and the calculation of decoration area and design density. The size and decoration measures distinguished the specialised jars in the early Lapita site on New Caledonia from the more standardised, utilitarian pots of late Lapita age from Fiji, and although some measurement error from resizing is expected, the significant differences found between specialised and standardised ceramics appears robust. Results suggest that the specialised function of decorated Lapita wares was expressed in larger overall vessel size, and greater size variability within a vessel type, although an intra-assemblage analysis of decorated versus utilitarian containers from an early Lapita assemblage is required to confirm the hypothesis.

The specialized ceramics of Lapita culture were likely to have had a range of purposes, including in burial ritual, as demonstrated by the association of Lapita vessels with human remains in Vanuatu (Bedford et al. 2006, this volume). However, dentate-stamped and other decorated vessels are often found at sites with remains otherwise indicative of domestic habitation. Chiu (2005) has suggested that some dentate-stamped designs were clan markings and new designs were generated by inter-clan marriages (see also Washburn 1999), which implies that dentate-stamped designs were employed in formal inter-group events.

This idea might be further examined for the carinated jars found in a pit at the WKO013A site. The vessels are all highly decorated, although the dentate-stamped decoration applied to the largest jars appears to be more open and less dense compared with smaller jars (an observation that might be tested using a smaller grid to measure design density). When the size of the 10 carinated jars is taken into account there is a design division between the largest-sized jars and the smaller jars. Three of the four largest vessels were decorated with the 'interlocking check' design (Sand et al. 1998:37), with one representing a simplified form of the design with a vertical 'eye'. Three of the 'smaller' carinated jars have a design featuring an enveloped crescent (Figure 3).

Temper analysis for each vessel is not yet available, so the possibility that vessels with similar designs were made from similar temper sands and clays, indicating the presence of two social groups, remains to be tested (Sand pers. comm. found that different dentate-tools were used to decorate jars with the interlocking check design). In a wider study of ceramic tempers, Chiu (2003: 176) found there was no evidence for exotic temper at the WKO013A site, and the Lapita potters probably collected temper sands from "right beside their houses or workshops to a distance of 8-15 km." The distance is similar to that recorded for ethnographic potting communities, where most travelled a distance of $10 \mathrm{~km}$ or less to obtain temper materials (Arnold 1985:49; Rice 1987). This implies that dentate-stamped vessels were usually made with local materials and produced primarily for local communities.

The New Caledonian jars exhibit significant size variability, and overall they are larger than utilitarian containers. The production of over-sized material-culture has received little attention in material culture studies, although it is a relatively common phenomenon. In New Zealand, for instance, some burial ornaments at the early Wairau Bar site were much larger than those made in tropical East Polynesia (Duff 1956), and Leach (1993) notes the presence of very large stone adzes in Polynesia. Malinowski (in Sheppard 1996:103) and others have noted that the size of an object is an attribute useful for conveying social information. Large ceremonial adzes in the Trobriand islands, for instance, were commissioned by chiefs who supported craft specialists with gifts of surplus food: 'Both producer and consumer like to make or acquire an article which is strikingly big, or strikingly well finished, or of a strikingly fine material, even though in the process 


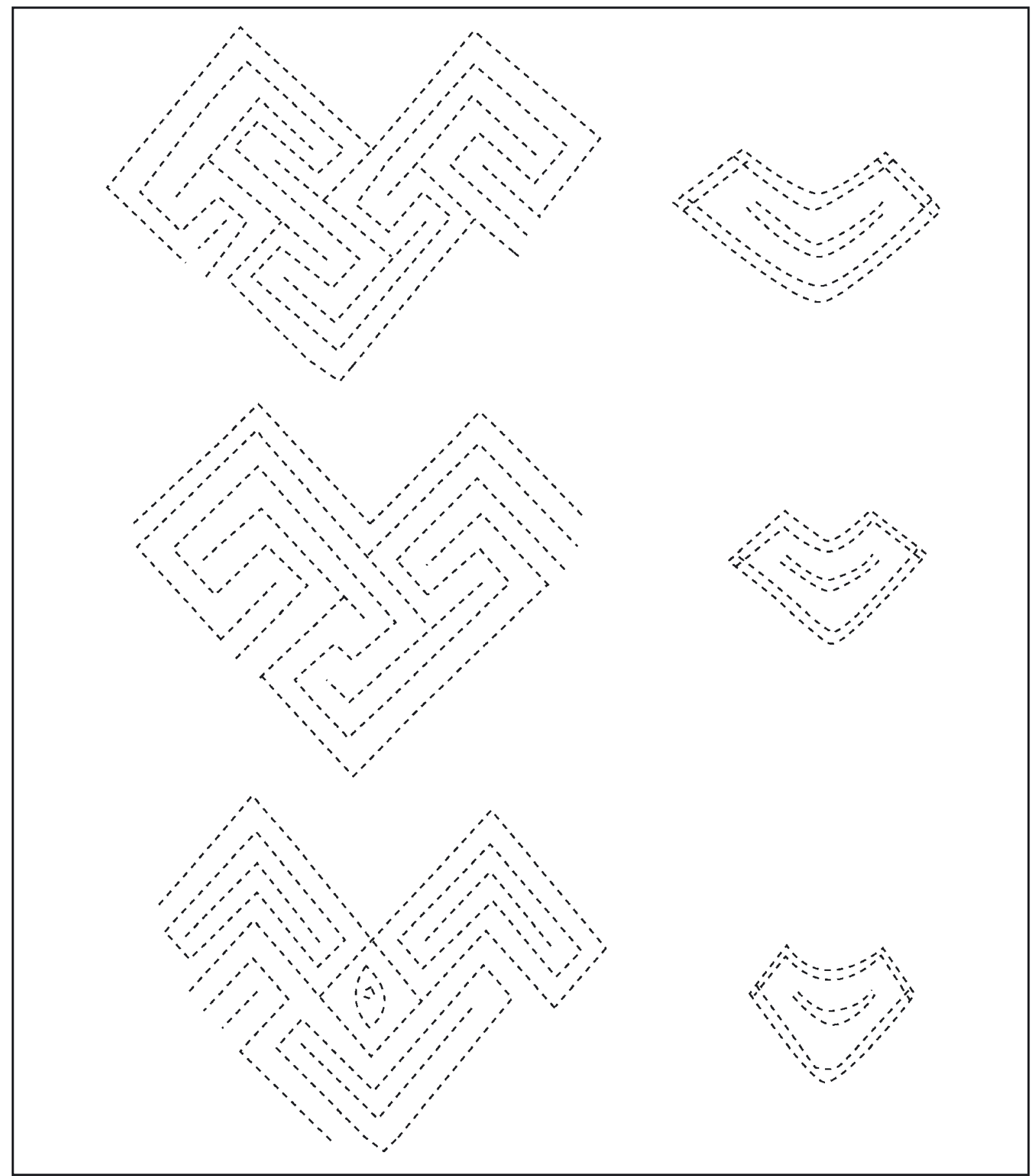

Fig. 3. Similar dentate-stamped designs found on New Caledonia carinated jars from the pottery pit at the WK0013A site. Left: 'Interlocking check' design variants on three of the largest reconstructed vessels. Right: 'Enclosed crescent pattern on three smaller carinated jars (see Sand et al. (1998) and Sand (1999) for vessel decoration).

the article were to become unwieldy, breakable, and good for nothing but display... they might still be placed in specially beautiful handles and carried by a man of rank during a ceremony'. Unlike large ornaments and adzes that most likely signalled the high status of individuals (cf. Blanton et al. 1996), the enhanced visibility of dentate-stamped jars points to their use in collective events, as does the volume of the carinated jars. The average volume of the utilitarian Sigatoka pots, calculated with the algorithm of Senior and Birnie (1995), was ca. 8 litres, while the largest carinated jars from the WKO013A site had volumes ca. 8-13 times larger. What 
was placed in the carinated jars might be discoverable by an analysis of residues, but the large vessel volumes suggest the contents were being utilised by larger groups than the family units, which are presumed to have produced the utilitarian late-Lapita pots at Sigatoka.

Vessel designs include at least two sets (interlocking check and enclosed crescent), as well as 'eye' and 'face' motifs, and further study of vessel temper and tool markings may link vessels with particular potters or 'clan' groups (i.e. Chiu 2005). Societies with poorly developed hierarchical divisions are characterised by Wason (1994: 119) as having designs made up of the repetition of simple elements arranged symmetrically (see also Washburn 1999), the inclusion of empty or irrelevant space, and the delineation of figures without enclosures. These traits apply in general to the decoration on the carinated jars, and the termination of two of the largest carinated jars (and perhaps all of the vessels found in the pit) by punching a hole in the base of the vessel (Sand et al. 1998:37) also attests to purposeful destruction, rather than the accumulation of 'wealth' objects.

The specific meaning of the designs is, of course, uncertain, although they likely represent a belief system that was integral to group identity during Lapita expansion, and in abstract and figurative form was used to mark specialised Lapita vessels. Among colonising populations entering new environments, like those of Remote Oceania, where the impetus to social fragmentation was essentially unconstrained by the relative abundance of land and wild food resources, symbols, events and performances emphasising social cohesion would have been particularly important (i.e. at key events such as marriage, death, group feasting). Applied to specialised Lapita ceramics, such a view is somewhat similar to signaling theory (see also Summerhayes and Allen this volume), where the 'cost' of manufacturing, using and removing non-utilitarian vessels by relatively small colonising populations was repaid by their role in maintaining the connectivity between social groups that was crucial to the long-term biological survival of colonists (Moore 2001). Costly signaling along with other theories of profligate production and consumption (e.g. Bliege Bird and Smith 2005), might also help to explain technical deficiencies in the manufacture of Lapita vessels (Ambrose 1997), and why colonisation deposits of different ages in Remote Oceania, such as those of those of Lapita culture and Archaic East Polynesian culture in New Zealand, often appear far richer in material culture and faunal remains than those of later occupation phases.

\section{References}

Allen, J., S.G. Holdaway and R. Fullagar 1997. Identifying specialisation, production and exchange in the archaeological record: The case of shell bead manufacture on Motupore Island, Papua. Archaeology in Oceania 32: 13-38.

Ambrose, W.R. 1997. Contradictions in Lapita pottery, a composite clone. Antiquity 71: 525-538.

Arnold, D.E. 1985. Ceramic theory and cultural process. Cambridge: Cambridge University Press.

Bedford, S. 2006. The Pacific's earliest painted pottery: an added layer of intrigue to the Lapita debate and beyond. Antiquity 80: 554-557.

Bedford, S., M. Spriggs and R. Regenvanu. 2006. The Teouma Lapita site and the early human settlement of the Pacific Islands. Antiquity 80:812-828.

Bellwood, P. 1978. Man's conquest of the Pacific. Auckland: Collins.

Benco, N.L. 1988. Morphological standardization: An approach to the study of craft specialization. In C.C. Kolb and M. Kirkpatrick (eds), A pot for all reasons: Ceramic ecology revisited, pp. 57-72. Philadelphia: Temple University.

Best, S. 2002. Lapita: A view from the east. Auckland: New Zealand Archaeological Association Monograph 24.

Birks, L. 1973. Archaeological Excavations at Sigatoka dune site, Fiji. Suva: Bulletin of the Fiji Museum No.1.

Blackman, M.J., G.J. Stein and P.B. Vandiver 1993. The standardization hypothesis and ceramic mass production: Technological, compositional, and metric indexes of craft specialization at Tell Leilan, Syria. American Antiquity 58:60-80. 
Blanton, R.E., G.M. Feinman, S.A. Kowalewski and P.N. Peregrine 1996. A dual-process theory for the evolution of Mesoamerican civilization. Current Anthropology 37: 1-14.

Bliege Bird, R. and E.A. Smith 2005. Signaling theory, strategic interaction, and symbolic capital. Current Anthropology 46: 221-248.

Burley, D.V. and W.R. Dickinson 2001. Origin and significance of a founding settlement in Polynesia. Proceedings of the National Academy of Sciences of the USA 98: 11829-11831.

Burley, D.V., A. Storey and J. Witt 2002. On the definition and implications of eastern Lapita ceramics in Tonga. In S. Bedford, C. Sand and D. Burley (eds), Fifty years in the field. Essays in honour and celebration of Richard Shutler Jr's archaeological career, pp. 213-225. New Zealand Archaeological Association Monograph 25.

Burley, D.V. and W.R. Dickinson 2004. Late Lapita occupation and its ceramic assemblage at the Sigatoka Sand Dune site, Fiji, and their place in Oceanic prehistory. Archaeology in Oceania 39:12-25.

Chiu, S. 2003. Social and economic meanings of Lapita pottery: a New Caledonian case. In C. Sand (ed.), Pacific Archaeology: Assessments and Prospects, pp. 159-182. Nouméa: Les cahiers de l'archéologie en NouvelleCalédonie 15.

Chiu, S. 2005. Meanings of a Lapita face: Materialized social memory in ancient house societies. Taiwan Journal of Anthropology 3: 1-47.

Clough. R. 1992. Firing temperatures and the analysis of Oceanic ceramics: a study of Lapita ceramics from Reef/ Santa Cruz, Solomon Islands. In J-C. Galipaud (ed.), Poterie Lapita et Peuplement, pp. 177-192. Nouméa: ORSTOM.

Costin, C.L. and M.B. Hagstrum 1995. Standardization, labor investment, skill, and the organization of ceramic production in late Prehispanic Highland Peru. American Antiquity 60: 619-639.

DeBoer, W.R. 1980. Vessel shape from rim sherds: an experiment of the effect of the individual illustrator. Journal of Field Archaeology 7:131-135.

Duff, R. 1956. The Moa-hunter period of Maori culture. Wellington: New Zealand Government Printer.

Golson, J. 1971. Lapita ware and its transformations. In: R.C. Green and M. Kelly (eds.), Studies in Oceanic Culture History, Vol. 2, pp. 67-76. Hawaii: Pacific Anthropological Records No. 12.

Gosselain, O.P. 1992. Bonfire of the enquiries. Pottery firing temperatures in archaeology: what for? Journal of Archaeological Science 19: 243-259.

Green, R.C. 1982. Models of the Lapita cultural complex: an evaluation of some proposals. New Zealand Journal of Archaeology 4: 7-20.

Hintze, J.L. 1997. NCSS 97. Statistical system for Windows. Salt Lake City: Number cruncher statistical systems.

Hunt, T.L. 1988. Lapita ceramic technological and composition studies: A critical review. In P.V. Kirch and T.L. Hunt (eds), Archaeology of the Lapita cultural complex: A critical review, pp. 49-60. Seattle: Thomas Burke Memorial Washington State Museum Research Report No. 5.

Hunt, T.L. 1989. Lapita ceramic exchange in the Mussau Islands, Papua New Guinea. Unpublished PhD thesis, University of Washington.

Irwin, G. 1985. The emergence of Mailu: as a central place in coastal Papuan prehistory. Department of Prehistory, Australian National University. Terra Australis 10.

Kirch, P.V. 1990. Specialization and exchange in the Lapita complex of Oceania. Asian Perspectives 29:117-133.

Kirch, P.V. 1997. The Lapita Peoples. Ancestors of the Oceanic World. Blackwell: Oxford.

Leach, H. 1993. The role of major quarries in Polynesian prehistory. In M.W. Graves and R.C. Green (eds), The evolution and organisation of prehistoric society in Polynesia, pp. 33-42. Auckland: New Zealand Archaeological Association Monograph 19.

Longacre, W.A. 1999. Standardisation and specialisation: What's the link? In J.M. Skibo and G.M. Feinman (eds), Pottery and people. A Dynamic interaction, pp. 44-58. Salt Lake City: University of Utah Press. 
Marshall, Y. 1985. Who made the Lapita pots? A case study in gender archaeology. Journal of the Polynesian Society 94:205-233.

Moore, J.H. 2001. Evaluating five models of human colonization. American Anthropologist 103:395-408.

Plog, S. 1985. Estimating vessel orifice diameters: measurement methods and measurement error. In B.A. Nelson (ed.), Decoding prehistoric ceramics, pp. 243-253. Carbondale and Edwardsville: Southern Illinois University Press.

Rice, P.M. 1981. Evolution of specialized pottery production: A trial model. Current Anthropology 22:219-240.

Rice, P.M. 1987. Pottery Analysis. A sourcebook. Chicago: The University of Chicago Press.

Sand, S., K. Coote, J. Bole, and A. Ouetcho 1998. A pottery pit at locality WKO013A, Lapita (New Caledonia). Archaeology in Oceania 33:37-43.

Sand, C. 1999. Archaeology of the Origins: New Caledonia's Lapita. Les cahiers de l'archéologie en Nouvelle-Calédonie Volume 10.

Sand, C. 2001. Evolutions in the Lapita cultural complex: a view from the Southern Lapita province. Archaeology in Oceania 36:65-76.

Senior, L.M. and D.P. Birnie 1995. Accurately estimating vessel volume from profile illustrations. American Antiquity 60:319-334.

Sheppard, P.J. 1996. Hard rock: Archaeological implications of chert sourcing in Near and Remote Oceania. In J. Davidson, G. Irwin, B.F. Leach, A. Pawley and D. Brown (eds), Oceanic Culture History: Essays in honour of Roger Green, pp. 99-115. New Zealand Journal of Archaeology Special Publication, New Zealand.

Spriggs, M. 1990. The changing face of Lapita: Transformation of a design. In M. Spriggs (ed.), Lapita design, form and composition. Proceedings of the Lapita Design Workshop, Canberra, Australia-December 1988, pp. 83-122. Canberra: Department of Prehistory, Australian National University. Occasional Papers in Prehistory No. 19.

Summerhayes, G. 2000. What's in a pot? In A. Anderson and T. Murray (eds), Australian Archaeologist. Collected papers in honour of Jim Allen, pp. 291-307. Canberra: Coombs Academic Publishing, Australian National University.

Summerhayes, G. R. 2001. Lapita in the far west: recent developments. Archaeology in Oceania 36: 53-63.

Vanderwal, R.L. 1973. Prehistoric studies in central coastal Papua. Unpublished PhD thesis, Australian National University.

Washburn, D. 1999. Perceptual anthropology: The cultural salience of Symmetry. American Anthropologist 101: 547-562.

Wason, P.K. 1994. The archaeology of rank. Cambridge: Cambridge University Press. 